\title{
Preexposure prophylaxis-related stigma: strategies to improve uptake and adherence - a narrative review
}

This article was published in the following Dove Press journal:

HIVIAIDS - Research and Palliative Care

13 October 2015

Number of times this article has been viewed

\section{Bridget G Haire}

Kirby Institute for Infection and Immunity in Society, University of New South Wales, Sydney, NSW, Australia
Correspondence: Bridget Haire Kirby Institute for Infection and Immunity in Society, Level 6, Wallace Wurth Building, Kensington Campus, University of New South Wales, Sydney,

NSW 2052, Australia

Email b.haire@unsw.edu.au
Abstract: Despite high levels of efficacy, the implementation of preexposure prophylaxis (PrEP) as a strategy to prevent new HIV infection has been slow. Studies show that PrEP works so long as it is taken, making adherence one of the great challenges of effective PrEP implementation alongside issues of access and uptake. Given that effective PrEP use requires ongoing self-administration of pills by people at high risk of HIV acquisition, it is a strategy best understood not as simply biomedical, but as biobehavioral or biopsychosocial, meaning that that social, psychological, cultural, and structural factors all contribute to the success or failure of the intervention. The willingness of people at risk of HIV to take up and adhere to PrEP depends greatly upon social understandings - whether it is seen as effective, as a healthy option, and a socially acceptable strategy for preventing HIV. Stigma - unfavorable associations - can negatively influence the implementation of PrEP. Because it is associated with high-risk sexual activity, PrEP risks multiple stigmas that can differ according to specific cultural conditions. This includes the stigma of being related to HIV (which may also relate to other stigmas, such as homosexuality, sex work, and/or drug use) and the stigma of PrEP being an alternative to condoms (as condom use is associated with responsible sexual activity). PrEP-related stigma has emerged as a significant social harm that can arise from PrEP research participation, reported by trial participants from a range of different trial sites, different trial populations, and spanning different continents. Social marketing needs to redress PrEP-related stigmas through health promotion campaigns aimed at clinicians, HIV-affected communities, and people at high risk of HIV who might benefit from PrEP access. PrEP access needs to be reframed as a positive and responsible option to help people remain HIV-negative.

Keywords: HIV prevention, discrimination, PrEP

\section{Introduction}

With more than two million new HIV infections each year, new strategies for HIV prevention are a global priority. ${ }^{1}$ Increased access to antiretroviral (ARV) therapy reduces the risk of sexual transmission from people with HIV to partners; however, ongoing HIV incidence can be sustained by people who are unaware of their infection. New prevention interventions that are targeted toward HIV-negative people who are at high risk of HIV acquisition are thus urgently required. ${ }^{2}$ Paradoxically, the implementation of one such promising strategy - preexposure prophylaxis or 'PrEP' - has been sluggish $^{3}$ and dogged with controversy. ${ }^{4}$

PrEP currently involves the use of two coformulated antiretroviral drugs, tenofovir disoproxil fumarate and emtricitabine (TDF/FTC; brand name Truvada), taken as a combined oral tablet by HIV-negative people to reduce the risk of HIV infection 
(it is likely that other drugs might be also licensed for this indication in the future). The antiretroviral TDF has also been trialed as PrEP, both in oral form ${ }^{5-7}$ and as a gel for topical vaginal use of PrEP. ${ }^{8}$ These studies demonstrated safety ${ }^{5-7}$ and efficacy, ${ }^{6,7}$ but at lower levels than the combined form of the drug.

To date, the United States is the only country to have licensed TDF/FTC-based PrEP, and the terms of licensure stipulate that it is to be as in addition to safer sex practices, not as an alternative. ${ }^{9}$ The World Health Organization has issued guidelines recommending that PrEP should be available as an additional risk-reduction strategy for men who have sex with men (MSM) and HIV-negative sex partners of HIV-positive people in all epidemic settings, and that it should be considered for transgendered women who have sex with men; ${ }^{10}$ however, there has been limited implementation of this to date. Outside the US, several countries including South Africa and Australia have produced clinical guidelines for "off-label" use of PrEP (prescription of the drugs for an indication not licensed in the particular country), while within the US some 3 years after the Food and Drug Administration (FDA) approval, PrEP uptake remains relatively low. ${ }^{3}$ Globally, most PrEP access has occurred through "demonstration sites" - projects that provide limited access to PrEP to people who are assessed to be at high risk of HIV acquisition, with an implementation research context. ${ }^{1-13}$

Since the FDA licensure in 2012, the evidence base for PrEP has grown steadily. The FDA approved PrEP based on the efficacy results of two studies - one in $\mathrm{MSM}^{14}$ and the other in serodiscordant couples (sexual partners where one partner is HIV infected and the other is not). ${ }^{6} \mathrm{~A}$ subanalysis of the MSM study (known as the Pre-Exposure Prophylaxis Initiative $[\mathrm{iPrEX}])$ showed that with optimal adherence, efficacy was more than $90 \%,{ }^{15}$ however, there were some dissident voices on the FDA panel who argued that the strength of evidence for PrEP's efficacy was insufficiently robust, ${ }^{16}$ as two major PrEP studies in African women had had futility findings. ${ }^{17,18}$ The futility findings were later attributed predominantly to poor adherence in the respective cohorts, although there is some evidence that HIV protection for vaginal exposure requires higher levels of adherence to PrEP. ${ }^{17-21}$ Further results from randomized control trials (RCTs) have since consolidated the efficacy of PrEP in other populations heterosexual men and women ${ }^{22}$ and people who inject drugs, ${ }^{7}$ with the overall risk reduction observed in RCTs ranging from $0 \%$ to $86 \%{ }^{6-8,14,17-18,22,23}$ The highest risk reduction observed to date in an RCT used an intermittent, rather than daily, dosing strategy in MSM.$^{23}$ In addition, a series of results from demonstration sites ${ }^{24,25}$ and implementation studies ${ }^{26}$ have shown PrEP to be highly effective in reducing the risk of HIV acquisition.

Together, these studies show that PrEP works so long as it is taken, making adherence one of the great challenges of effective PrEP implementation - the others being access and uptake. As behavioral scientist K Rivet Amico has noted, ${ }^{27}$ given that effective PrEP use requires ongoing self-administration of pills, it is a strategy best understood not as simply biomedical, but as biobehavioral or biopsychosocial, meaning that that social, psychological, cultural, and structural factors all contribute to the success or failure of the intervention. Accordingly, this review will necessarily include some literature outside standard medical journals in order to reflect relevant psychosocial factors.

The willingness of people at risk of HIV to take up PrEP depends greatly upon social understandings - whether it is seen as effective, as a healthy option, and a socially acceptable strategy for preventing HIV - in addition to cultural and structural factors. ${ }^{28}$ How clinicians view PrEP - and people who seek PrEP - also affects uptake, as does the adherence support that patients receive. Unfavorable associations with PrEP - stigma - can negatively influence the implementation of PrEP. It is thus in the context of adherence, access, and uptake issues that this article will review the interrelationship between stigma and the use of PrEP.

\section{Stigma}

Stigma is best understood as a social practice that "marks" or associates something with a form of difference that is negatively valued. ${ }^{29}$ Goffman coined the term "spoiled identity" to describe the impact of stigma upon people who become stigmatized through being identified with something that is generally viewed in a negative way in a particular society. ${ }^{30}$ HIV has long been understood as a stigmatized infection, due at least in part to associations with homosexuality, so-called "promiscuity", sex work, and injecting drug use, in addition to the actual properties of the infection. ${ }^{31}$ Importantly, stigma is the product of how social groups project negative difference onto particular things or attributes, and how the people who perceive a risk of being stigmatized respond to protect themselves. So while a gay man might be out and proud in the streets of San Francisco, he might opt to conceal his sexuality on the streets of Lagos. People frequently adapt their social presentation in different contexts to avoid facing the stigmatizing projections of others, as well as for personal safety.

When HIV first emerged in gay communities in the 1980s, one of the ways that these communities fought back against 
HIV-related stigma was the invention of safer sex - the promotion and celebration of sex that minimized the risk of HIV transmission. Safer sex showed that the sociopolitical gains of the Gay Liberation movement were not defeated by this new epidemic, and that gay communities and sex cultures could survive. Sociologist Jeffry Weeks noted, "the discourse of safer sex is precisely about balancing individual need and responsibility to others in a community of identity whose organising principle is the avoidance of infection and the provisions of mutual support". ${ }^{32}$ Weeks dubbed this phenomenon "sexual citizenship". ${ }^{32}$ Arguably, the condom was its emblem, with condom use being the marker of the "good" (responsible and community-aware) gay man. Thus, condom-protected sex attained a symbolic meaning over and above being barrier protection from a sexually transmissible virus for populations at risk of acquiring HIV. It should also be noted that while meanings that derive from gay communities may have certain international applicability (for example, between the US, Western Europe, Australia, New Zealand, and the United Kingdom), MSM globally are culturally diverse so assumptions should not be made that stigma will be experienced in the same way across different cultural settings.

Due to its association with high-risk sexual activity, PrEP risks multiple stigmas that can differ according to specific cultural conditions. This includes but is not limited to the stigma of being related to HIV (which in some cases is also related to other stigmas, such as homosexuality, sex work, and/or drug use $)^{29}$ and the stigma of PrEP being an alternative to condoms (and thus missing the symbolic virtues attached to consistent condom use). This context helps to make sense of the slow uptake of PrEP in the US, and the vociferous opposition to it from American Healthcare Foundation president Michael Weinstein, who argued against the licensure of TDF/FTC-based PrEP in $2012^{33}$ and has continued to conduct a negative press campaign over 3 years. ${ }^{34}$ Weinstein's dismissal of PrEP as a "party drug" gave rise to an ironic/ subversive new identity category in some gay communities - self-identified "Truvada whores". ${ }^{35,36}$ While this was initially an insult, its reappropriation by self-identified PrEP users challenges the negativity of the label $^{37}$ and begs the question: why should people feel ashamed, or be stigmatized, for taking active steps to prevent HIV acquisition, and how can this situation be ameliorated?

\section{Stigma findings in PrEP research}

PrEP-related stigma has emerged as a significant social harm that can arise from PrEP research participation, reported by trial participants from a range of different trial sites, different trial populations, and spanning different continents. ${ }^{38-40}$

In a study of PrEP demonstration sites in San Francisco, Liu et al found that stigma was the most commonly reported social harm arising from study participation, with 15 of 20 listed social harms relating to stigma. The participants reported feeling stigmatized by medical providers, friends, and sex partners. ${ }^{38}$

Similarly, in a qualitative study of MSM who participated in the PrEX study in Chiang Mai, Thailand, Tangmunkongvorakul et al found that stigma was a challenge to medication adherence, and noted several different kinds of stigma experienced by study participants. The first was stigma related to nondisclosure of sexual identity, usually relating to participants living away from home, who when visiting parents then had difficulty with taking medication as they did not wish to disclose study participation. The second form of stigma related both to the possibility of being assumed to be HIV-positive if seen taking the medication (the pills are large and distinctively blue colored), and to potentially being labeled as a high-risk gay man (a "Truvada whore" in the non-rehabilitated sense). Finally, the authors found conflict with primary sexual partners related to the perception that study participation may be a marker of high-risk sexual activity occurring outside the relationship, and thus a threat to the primary relationship. Each of these forms of stigma were seen as an incentive to avoid being seen taking the study medication, or disclosing study participation. ${ }^{39}$

In a clinical trial in Kenya of the safety, acceptability, and adherence that compared daily dosing to intermittent PrEP dosing in MSM and female sex workers (FSW), Van der Elst et $\mathrm{al}^{40}$ found that the social impacts of PrEP included stigma, being implicated in rumors, and experiencing relationship difficulties due misapprehension of HIV status. As in the Chiang Mai trial, participants in this Kenyan study also reported that the color of the PrEP pill made it too identifiable as an antiretroviral, and that it stained the tongue, meaning that concerned participants had to clean their mouths after swallowing the pill. If suspected of being HIV-positive, PrEP users reported that they could be vulnerable to gossip, discrimination in the community, and, for those engaged in sex work, loss of clients. One study participant attributed his marital breakdown to his wife's suspicions regarding his HIV status after seeing him taking PrEP. Stigma related to being seen taking antiretroviral drugs, whether real or perceived, was linked to avoiding doses in company, which could compromise adherence ${ }^{40}$ The authors found that the social challenges for participants and likelihood of experiencing 
HIV-related stigma mean that the acceptability of PrEP needs to be considered at the community level, and they noted that reports of stigma and discrimination were linked with participants with low adherence or study discontinuation, suggesting that stigma and discrimination may play a major role in both adherence and acceptability.

In contrast to the studies in Kenyan sites, Chiang Mai, and San Francisco, a qualitative study on serodiscordant couples who participated in the Partners PrEP study in Ugandan sites found that PrEP had a positive influence on relationship dynamics. ${ }^{41}$ The social and relational differences between these two populations help to explain the discrepant findings. The Thai MSM were recruited as individuals at high risk of HIV acquisition, while the Partners PrEP participants were recruited in a relational capacity - because their risk of HIV derived from their long-term sexual partner. Study authors Ware et al suggested that for these Partners PrEP participants and their HIV-positive partners, PrEP represented a solution to what they dubbed "the discordance dilemma", rather than invoking the fear of partner infidelity or stigma related to socalled "promiscuity". This "discordance dilemma" was the relationship stress caused by one member of a couple being diagnosed with HIV, with the possibility of past infidelity this suggests, and the ongoing need for protected sex it gives rise to. In this context, the authors suggest PrEP was associated with meanings such as hope for the future of the relationship, and thus adherence was a positive process within the relationship, not associated with stigma. ${ }^{41}$

Five recent studies presented at the 2015 International AIDS Society (IAS) Conference in Vancouver show that while PrEP uptake and adherence may be improving, there are significant differences in particular populations which are likely related to social determinants. Preliminary data from the PrEP Brazil demonstration site showed that those with the greatest HIV risk (defined as having two or more condomless sex partners) were more likely to enroll. ${ }^{42}$ This study also included the highest number of transgender women in a PrEP study to date (24 women), which is a positive development for this population group which faces disproportionately high risk of HIV acquisition in addition to being stigmatized. In Botswana, former participants from the TDF2 efficacy study ${ }^{22}$ enrolled in an open-label demonstration site reported very high levels of adherence, and self-report appeared to correlate with drug blood levels in the subsample whose serum was tested. ${ }^{43}$ No HIV acquisition occurred in this study of 229 participants. While this was not an efficacy study, it adds to the evidence that PrEP can be utilized effectively in African heterosexual populations. ${ }^{43}$
Further evidence on PrEP use in African women and other populations was reported from a multisite randomized trial known as HPTN 067.44 This study compared intermittent PrEP (both time-driven dosing and coital event-driven dosing) to daily PrEP use in three distinct populations: MSM and transgender women in Harlem, USA and Bangkok, Thailand, and women in Cape Town, South Africa. Each site was randomized separately to the three arms to allow capture of culturally distinct differences between study populations. In the Cape Town women, the daily dosing schedule achieved the highest drug coverage of sexual events (five seroconversion occurred at this site, with one seroconversion in the daily arm and two in each of the other arms, but all who seroconverted showed no blood levels of PrEP, suggesting nonadherence). In the Bangkok population, coverage was high in all arms, with no seroconversions. In the Harlem population, one seroconversion occurred in the daily arm, in an individual whose blood levels showed very low levels of PrEP, suggesting poor adherence. In accompanying qualitative research, some participants noted that taking a pill daily was easier than taking pills intermittently, and researchers described an association between pill-taking and stigma related both to perceived HIV risk and so-called "promiscuity". ${ }^{44}$

Two US-based studies presented at the Vancouver IAS conference showed an adherence differential according to whether participants reported themselves as White, Latino, or Black, with Black participants having lower adherence. In the US Demo project, which had 557 gay or bisexual male and transgender female participants in three US cities, 91\% of White participants had protective drug levels in their blood, while $77 \%$ of Latino and only $57 \%$ of Black participants did. ${ }^{45}$ Similarly, a study of young gay and bisexual men (aged 18-22 years), Adolescent Trials Network $110,{ }^{46}$ showed considerably lower adherence in Black and mixed-race men, with drug levels not reaching protective levels in Black participants. For all participants in this study, adherence dropped off when study visits moved from monthly to quarterly, suggesting that frequent monitoring may be important for young men. While the differential adherence for Black participants is likely to be caused by complex and interconnecting social determinants, it is not inconceivable that various forms of stigma may play a part in this.

\section{Stigma in acceptability studies}

Stigma-related issues raised in studies on PrEP acceptability, as distinct from studies where participants were actually receiving PrEP or placebo through a clinical trial, are generally not found in the studies published prior to $2012 .{ }^{47-53}$ As 
social scientist Martin Holt noted in a review on acceptability literature, much of this early research on acceptability was assessed on the basis of simple single-answer survey questions, such as "If PrEP were at least $80 \%$ effective and available, would you use it?", a format that does not allow respondents to consider the pros and cons of PrEP as a strategy. ${ }^{54}$

In studies published in 2012 and later, there is greater attention paid to stigma in acceptability research, and a range of findings related to the interrelationships between uptake, adherence, and stigma.

Smith et al found that the anticipated negative reaction of peers, friends, and family members was viewed as a factor that could mitigate against PrEP uptake, in a study of the attitudes of young African American adults (18-24 years). ${ }^{55}$ These participants reported that they expected disclosure of PrEP use (deliberate of otherwise) would lead others to believe they were either engaging in (stigmatized) high-risk sex or that they were in fact HIV-positive, considerations also noted by participants in PrEP clinical and implementation studies. ${ }^{39,40}$

This concern about being stigmatized in association with high-risk sex (also called "promiscuity") was echoed in a PrEP acceptability study conducted in Lima, Peru that enrolled MSM, FSW, and male-to-female transgendered women. ${ }^{56}$ Galea et al found that MSM participants reported that they were unlikely to disclose PrEP use to family due to fear of rejection or being seen as "promiscuous". All groups (MSM, FSW, and transgendered women) were supportive of selective disclosure of PrEP use within their specific social networks, for example, to other sex workers or friends, while disclosure of PrEP to clients or casual sex partners was not supported. General concern about stigma and mistrust of health professionals was also reported by these participants, which could impact on uptake. ${ }^{56}$

Being assumed by others to have HIV was identified as a major concern with regard to stigma in a range of studies. ${ }^{39,40,55,57,58}$ In a qualitative study of sexual partnership and considerations for PrEP use in high-risk US-based MSM who reported recreational illegal drug use, Mimiaga et al found that participants feared that disclosure of PrEP use could lead to rejection and gossip, with gossip possibly based on the misapprehension of HIV-positive status. Thus stigma was a major concern in relation to casual sex partners, and a disincentive to disclosure of PrEP use. ${ }^{57}$ Participants perceived discussions about PrEP use as particularly difficult in scenarios involving recreational drug and alcohol use such as clubs, sex-on-the-premises venues or private sex parties, as higher rates of HIV-related stigma might be experienced at such venues. ${ }^{57}$

In formative research conducted in Nigeria, Idoko et al found that being identified as someone needing PrEP was considered stigmatizing and, as discussed in the studies above, suggestive of HIV infection. ${ }^{59}$ The authors found that stigma was a potential barrier for PrEP use and discrimination a potential consequence of its use. They suggested that this may be a reflection of the stigma associated with ARV use for management of HIV infection and noted that stigma has been identified as a deterrent for uptake of HIV-related services including HIV testing, commencing ARV, and adherence to ARV drug regimens. Gender relations were also identified as a barrier to PrEP uptake, in a setting where couples' serodiscordance is usually identified through screening for HIV infection in women attending antenatal clinics.

Stigma related to homosexuality was identified as a disincentive to PrEP uptake for MSM in People's Republic of China in a survey-based study conducted by Jackson et al. The authors noted that while homosexuality was not illegal in People's Republic of China, it remains heavily stigmatized, and that there is evidence of both stigmatizing attitudes to MSM and people with HIV and breaches of confidentiality within medical settings. ${ }^{60}$

\section{Clinicians' responses to PrEP}

Given that legal use of PrEP requires a prescription, clinicians have an important role to play in access to and uptake of PrEP, in addition to having a role in providing the supportive monitoring of adherence and regular testing for HIV and sexually transmissible infections that PrEP requires in order to ensure that any intercurrent infection is swiftly diagnosed. The studies considered in this section are all North American.

In 2013, a US-based analysis of nationally representative prescription data revealed that nearly half of people taking PrEP were women. ${ }^{61}$ This data was somewhat troubling as the population group in the US that faces the greatest risk of seroconversion is Black MSM, ${ }^{62}$ so there was some suggestion that clinical judgment could be askew in perhaps underprescribing PrEP to men or, less likely, overprescribing to women.

Two studies of the awareness, attitudes, and practices of clinicians were published shortly after the major PrEP efficacy results were released. ${ }^{63}$ An online, cross-sectional survey of generalist and HIV specialist physicians in Massachusetts found that while knowledge in the populations increased overall following release of results, HIV providers had higher knowledge levels than generalists. Of the sample, $4 \%$ had 
prescribed PrEP and 95\% said that they would prescribe PrEP if it were a highly effective daily pill, but issues including drug-related toxicities; the potential development of drug resistance; potential for funds to be diverted from behavior HIV programs to biomedical programs; concerns over the efficacy data; and fear that PrEP could increase HIV risk behavior were all cited as concerns that would mitigate against prescribing. ${ }^{63}$

In a second online, cross-sectional survey of HIV practitioners recruited through the American Academy of HIV Medicine, 19\% said they had prescribed PrEP but listed similar concerns to the Massachusetts study, such as the potential for the development of drug resistance and for increases in risk behavior. In addition, they were concerned about nonadherence to PrEP and the cost of the strategy. ${ }^{64}$

Karris et al conducted a survey in 2013 of members of the Infectious Diseases Society of America's Emerging Infections Network, which had 573 respondents (48.8\% response rate). This ten-question survey was developed to evaluate the current practices and attitudes of PrEP among infectious disease experts who were members of the network. While the majority of respondents supported the provision of PrEP (74\%), only $9 \%$ had actually prescribed it. Further, a sizable minority reported that they were unsure about PrEP (14\%) and 12\% said they did not support it. Some of the reasons cited for non-provision of PrEP and for not supporting PrEP provision included the following: "concern about irresponsible sexual activity"; "If they won't use condoms they won't use pills"; "there are better prophylactics"; "moral issues"; and "medicine should not attempt to reverse bad behaviors artificially". These reasons are stigmatizing for: attaching inappropriate value judgments to sexual behavior; suggesting that nonadherence to one form of HIV risk reduction means an incapacity to adhere to another; attaching value judgments to different forms of HIV risk reduction; and moralizing about sexual behavior rather than placing protection of health above notions of sexual transgression or "bad behavior" ${ }^{65}$ In addition to discussion the attitudes of respondents, the authors noted that some of the concerns about PrEP reported in the survey may be connected with what they described as "vague" guidance from the Centers for Disease Control and Prevention as to how to assess "ongoing very high risk of acquiring HIV infection". Providing further risk assessment guidance was suggested. ${ }^{65}$

Sachdev et al conducted an online survey of physicians in the United States in 2012 to understand factors associated with the intention to prescribe PrEP. ${ }^{66}$ This survey sought to assess physicians' attitudes, self-efficacy, and normative beliefs, which, the authors hypothesized, drive the willingness or otherwise to prescribe PrEP. Of the 5,672 email invitations sent to eligible physicians, 146 completed the survey, a response rate of 9.7\%; and of this sample, $28 \%$ of physicians reported that they would be willing to prescribe PrEP to MSM, $30 \%$ to at-risk women, and $45 \%$ to HIVnegative patients in serodiscordant relationships in the next year. ${ }^{66}$

Mimiaga et al assessed Massachusetts-area physicians' awareness and comprehension of efficacy data, prescribing experience, and anticipated provision of PrEP using an online, quantitative survey ${ }^{67}$ To inform the content of future educational interventions for physicians, specific concerns and hypothetical motivators around PrEP provision were also assessed. This survey, which was completed by 115 physicians (an $18.4 \%$ response rate) following the release of the iPrEX study but before the FDA licensure, ${ }^{9}$ found that $28 \%$ of physicians thought that oral PrEP should not be available to all at-risk people. While this study is now relatively old, given the new data about PrEP efficacy and effectiveness that has been released since this study, the finding is nevertheless worrying, and is highly suggestive of stigma attached to the use of PrEP itself, or of stigmatizing attitudes to particular kinds of HIV risk.

Another study that raises concerns about how social biases and stigma might impact on the optimal uptake of PrEP is a study in medical students conducted by Calabrese et al. ${ }^{68}$ This study sought to explore whether racial stereotypes about "risk compensation" - increased high-risk behavior related to adoption of a biomedical prevention strategy - affected medical students' willingness to prescribe PrEP. It comprised an online survey and presented a clinical vignette of a gay male serodiscordant couple. The race of the HIV-positive and -negative partners was systematically manipulated, and the participants reported clinical judgments including risk compensation and willingness to prescribe PrEP. The study found that if the HIV-negative partner was described as Black, the students rated him as more likely to engage in "increased" unprotected sex as a result of PrEP, and this correlated with "decreased" willingness to prescribe PrEP. This study shows that unconscious biases affected the attitudes of participating medical students, and suggests that there could be a heightened risk of discriminatory prescription practices for PrEP given the discourses about "risk compensation" and the reliance upon clinical judgment regarding assessment of HIV risk required for PrEP prescription. 


\section{Risk compensation}

The substantive health threat contained in the concept of "risk compensation" is that as a result of using PrEP (or other riskreduction measure), people who are already at high risk of HIV acquisition will increase their risk practices, and that the protection offered by partially effective risk-reduction measures such as PrEP will not be effective enough. Mathematical modeling studies have shown that with risk compensation (and/or poor targeting and coverage of a new risk-reduction intervention), the expected public health gains from a new strategy such as PrEP could actually be reversed - infections could increase rather than decrease. ${ }^{69}$ The assumption behind risk compensation concern is that people will use PrEP instead of condoms, rather than as an adjunct, and that it will prove less effective. This has not been borne out in RCTs to date. ${ }^{62,70-72}$ It has also been suggested that risk compensation is more likely to occur in open-label studies ${ }^{73}$ which has also not been borne out in practice. For example, in the openaccess cohort study, iPrEX OLÉ, it was found that unblinded participants receiving PrEP self-reported a decrease in sex acts unprotected by condoms, and this was corroborated in decreases in syphilis incidence. ${ }^{74}$ Furthermore, when considering the relative benefits of risk-reduction approaches, it should be noted that real-world effectiveness of condoms (as distinct from efficacy when used perfectly) was recently assessed by Smith et al as providing $70 \%$ risk reduction. ${ }^{75}$

The studies on clinicians' attitudes to $\mathrm{PrEP}^{63-68}$ suggest that concerns about risk compensation may be disproportionate and could adversely affect prescribing behavior, thus negatively impacting appropriate uptake of PrEP by at-risk individuals due to clinicians acting as gate-keepers rather than conduits to access.

\section{Conclusion}

Good adherence to PrEP is absolutely critical to its effectiveness at both individual and public health levels, ${ }^{76}$ and adherence may be compromised in situations where there is a need to conceal PrEP use. A range of authors noted that there are lessons to be learned about PrEP uptake and adherence and the role of stigma from studies on ARV in people with HIV.49,50,59

Stigma related to PrEP does not exist in a vacuum, but is produced by social pressures that also stigmatize HIV infection and nonnormative sexualities and limit access to prevention and care services. The challenge for health promotion is to change the public discourse and to remove barriers.

PrEP is an important new strategy that offers HIVnegative people a new way to protect themselves from HIV.
While PrEP access needs to be targeted to high-risk populations, care needs to be taken so that PrEP use is not (further) stigmatized by social-marketing campaigns that present PrEP users as irresponsible. PrEP access needs to be reframed as a positive and responsible option to help people remain HIV-negative.

\section{Disclosure}

The author reports no conflicts of interest in this work.

\section{References}

1. 10 facts on HIV/AIDS [webpage on the Internet]. Geneva: World Health Organization. Available from: http://www.who.int/features/factfiles/hiv/ facts/en/index2.html. Accessed July 22, 2015

2. Haire B. Considering Pre-Exposure Prophylaxis: Do the Pros Outweigh the Cons as an HIV Prevention Strategy? LGBT Health. 2014; 1(4):253-255

3. Flash C, Landovitz R, Giler RM, et al. Two years of Truvada for preexposure prophylaxis utilization in the US. J Int AIDS Soc. 2014;17 (4 Suppl 3):19730.

4. Hunter P. HIV prevention drug Truvada focus of controversy [webpage on the Internet]. Toronto: Thestar.com; 2014 [updated November 23, 2014]. Available from: http://www.thestar.com/life/ health_wellness/2014/11/23/hiv_prevention_drug_truvada_focus_of_ controversy.html. Accessed July 22, 2015.

5. Peterson L, Taylor D, Roddy R, et al. Tenofovir disoproxil fumarate for prevention of HIV infection in women: a phase 2, double-blind, randomized, placebo-controlled trial. PLoS Clin Trials. 2007;2(5):e27.

6. Baeten JM, Donnell D, Ndase P, et al. Antiretroviral prophylaxis for HIV prevention in heterosexual men and women. New Engl J Med. 2012;367(5):399-410

7. Choopanya K, Martin M, Suntharasamai P, et al. Antiretroviral prophylaxis for HIV infection in injecting drug users in Bangkok, Thailand (the Bangkok Tenofovir Study): a randomised, double-blind, placebocontrolled phase 3 trial. Lancet. 2013;381(9883):2083-2090.

8. Abdool Karim Q, Abdool Karim SS, Frohlich JA, et al. Effectiveness and safety of tenofovir gel, an antiretroviral microbicide, for the prevention of HIV infection in women. Science. 2010;329(5996):1168-1174.

9. FDA approves first drug for reducing the risk of Sexually Acquired HIV Infection (News release) [webpage on the Internet]. Silver Spring: US Food and Drug Administration; 2012 [updated July 17, 2012]. Available from: http://www.fda.gov/NewsEvents/Newsroom/ PressAnnouncements/ucm312210.htm. Accessed July 10, 2015.

10. Consolidated guidelines on HIV prevention, diagnosis, treatment and care for key populations [webpage on the Internet]. Geneva: World Health Organization; 2014. Available from: http://who.int/hiv/pub/ guidelines/keypopulations/en. Accessed July 2, 2015.

11. Ongoing and Planned PrEP Demonstration and Implementation Studies [webpage on the Internet]. AVAC Global Advocacy for HIV Prevention; 2015. Available from: http://www.avac.org/resource/ongoing-andplanned-prep-demonstration-and-implementation-studies. Accessed July 22, 2015

12. Young I, McDaid L. How acceptable are antiretrovirals for the prevention of sexually transmitted HIV?: A review of research on the acceptability of oral pre-exposure prophylaxis and treatment as prevention. AIDS Behav. 2014;18(2):195-216.

13. PrEP Update for HIV Clinicians [webpage on the Internet]. Surry Hills: Australasian Society for HIV Medicine; 2015. Available from: http:// www.ashm.org.au/PrEP. Accessed July 17, 2015.

14. Grant RM, Lama JR, Anderson PL, et al. Preexposure chemoprophylaxis for HIV prevention in men who have sex with men. New Engl J Med. 2010;363(27):2587-2599. 
15. Anderson PL, Glidden DV, Liu A, et al. Emtricitabine-Tenofovir Concentrations and Pre-Exposure Prophylaxis Efficacy in Men Who Have Sex with Men. Science Translational Medicine. Sci Transl Med. 2012;4(151):151ra125.

16. Wood LV. Why I voted "no" to Truvada PrEP. Ann Intern Med. 2012; 157(7):519-520.

17. Van Damme, L, Corneli A, Ahmed K, et al. Preexposure prophylaxis for HIV infection among African women. New Engl J Med. 2012; 367(5):411-422.

18. Marrazzo JM, Ramjee G, Richardson BA, et al. Tenofovir-based preexposure prophylaxis for HIV Infection among African women. New Engl J Med. 2015;372(6):509-518.

19. Corneli AL, Deese J, Wang M, et al. FEM-PrEP: adherence patterns and factors associated with adherence to a daily oral study product for pre-exposure prophylaxis. J Acquir Immune Defic Synd. 2014; 66(3):324-331.

20. van der Straten A, Van Damme L, Haberer JE, Bangsberg DR. Unraveling the divergent results of pre-exposure prophylaxis trials for HIV prevention. AIDS. 2012;26(7):F13-F19.

21. van der Straten A, Stadler J, Luecke E, et al. Perspectives on use of oral and vaginal antiretrovirals for HIV prevention: the VOICE-C qualitative study in Johannesburg, South Africa. J Int AIDS Soc. 2014;17 (3 Supp 2):19146.

22. Thigpen MC, Kebaabetswe PM, Paxton LA, et al. Antiretroviral preexposure prophylaxis for heterosexual HIV transmission in Botswana. New Engl J Med. 2012;367(5):423-434.

23. Molina JM, Capitant C, Spire B, et al. On Demand PrEP With Oral TDF-FTC in MSM: Results of the ANRS Ipergay Trial. Presented at: 2015 CROI; February 23-26, 2015; Seattle. Abstract 23.

24. Glidden DV, Buchbinder SP, Anderson PL, et al. PrEP Engagement for HIV Prevention: Results From the iPrEx Open Label Extension (OLE). Presented at: 2015 CROI; February 23-26, 2015; Seattle. Abstract 970.

25. Baeten J, Heffron R, Kidoguchi L, et al. Near elimination of HIV transmission in a demonstration project of PrEP and ART. Presented at: 2015 CROI; February 23-26, 2015; Seattle. Abstract 24.

26. McCormack S, Dunn D. Pragmatic open-label randomised trial of preexposure prophylaxis: The PROUD study. Presented at: 2015 CROI; February 23-26, 2015; Seattle. Abstract 22LB.

27. Amico KR. Adherence to preexposure chemoprophylaxis: The behavioral bridge from efficacy to effectiveness. Curr Opin HIV AIDS. 2012;7(6):542-548.

28. Kippax S, Stephenson N. Beyond the distinction between biomedical and social dimensions of HIV prevention through the lens of a social public health. Am J Public Health. 2012;102(5):789-799.

29. Parker R, Aggleton P. HIV and AIDS-related stigma and discrimination: a conceptual framework and implications for action. Soc Sci Med. 2003;57(1):13-24.

30. Goffman E. Stigma: Notes on the Management of a Spoiled Identity. Englewood Cliffs: Prentice-Hall Inc.; 1963.

31. Bayer R. Private Acts, Social Consequences. New York: The Free Press; 1989.

32. Weeks J. The Sexual Citizen. Theory Cult Soc. 1998;15(3):35-52.

33. Young S. Panel recommends approving Truvada to prevent HIV infection [webpage on the Internet]. Atlanta: Cable News Network; 2012 [updated July 17, 2012]. Available from: http://edition.cnn.com/2012/05/10/ health/hiv-drug. Accessed July 17, 2015.

34. Garcia M. Why Michael Weinstein gets blamed for PrEP Myths [webpage on the Internet]. Advocate.com; 2014. Available from: http://www. advocate.com/31-days-prep/2014/10/31/why-michael-weinstein-getsblamed-prep-myths. Accessed July 7, 2015.

35. Glazek C. Why I am a Truvada whore [webpage on the Internet]. Out.com; 2014. Available from: http://www.out.com/entertainment/ popnography/2014/05/20/why-i-am-truvada-whore. Accessed July 17, 2015. Accessed July 7, 2015.

36. Burress J. 'Truvada Whore' Stigma Endures Among Doctors and LGBTs [webpage on the Internet]. Advocate.com; 2014. Available from: http://www.advocate.com/health/2014/08/11/truvada-whorestigma-endures-among-doctors-and-lgbts. Accessed July 7, 2015.
37. Galinsky AD, Hugenberg K, Groom C, Galen BV. The reappropriation of stigmatizing labels: Implications for social identity. Identity Issues in Groups (Research on Managing Groups and Teams). 2003;5: 221-256.

38. Liu A, Cohen S, Follansbee S, et al. Early experiences implementing pre-exposure prophylaxis (PrEP) for HIV prevention in San Francisco. PLoS Med. 2014;11(3):e1001613.

39. Tangmunkongvorakul A, Chariyalertsak S, Amico KR, et al. Facilitators and barriers to medication adherence in an HIV prevention study among men who have sex with men in the iPrEx study in Chiang Mai, Thailand. AIDS Care. 2013;25(8):961-967.

40. Van der Elst EM, Mbogua J, Operario D, et al. High acceptability of HIV pre-exposure prophylaxis but challenges in adherence and use: qualitative insights from a phase I trial of intermittent and daily PrEP in at-risk populations in Kenya. AIDS Behav. 2013;17(6):2162-2172.

41. Ware NC, Wyatt MA, Haberer JE, et al. What's love got to do with it? Explaining adherence to oral antiretroviral pre-exposure prophylaxis for hiv serodiscordant couples. J Acquir Immune Defic Synd. 2012; 59(5):463-468.

42. Hoagland B; Grinsztejn B, presenter. Pre-exposure prophylaxis (PrEP) uptake and associated factors among MSM and TGW in the PrEP Brasil demonstration project. Presented at: Eighth IAS Conference on HIV Pathogenesis, Treatment and Prevention (IAS 2015), Vancouver; July 19-22, 2015; Vancouver, BC. Abstract TUAC0205LB.

43. Henderson F, Taylor AW, Chirwa LI, et al. Characteristics and oral PrEP adherence in the TDF2 open-label extension in Botswana. Presented at: Eighth IAS Conference on HIV Pathogenesis, Treatment and Prevention (IAS 2015), Vancouver; July 19-22, 2015; Vancouver, BC. Abstract TUAC0203.

44. Baeten J, Celum C. HIV Prevention at IAS 2015 Vancouver [webpage on the Internet]. Available from: www.natap.org/2015/IAS/IAS_93.htm. Accessed August 19, 2015.

45. Liu A, Cohen S, Vittinghoff E, et al. Adherence, sexual behavior and HIV/STI incidence among men who have sex with men (MSM) and transgender women (TGW) in the US PrEP demonstration (Demo) project. Presented at: Eighth International AIDS Society Conference on HIV Pathogenesis, Treatment and Prevention, Vancouver; July 19-22, 2015; Vancouver, BC. Abstract TUAC0202.

46. Hosek S, Rudy B, Landowitz R, et al. An HIV pre-exposure prophylaxis (PrEP) demonstration project and safety study for young men who have sex with men in the United States (ATN 110). Presented at: Eighth International AIDS Society Conference on HIV Pathogenesis, Treatment and Prevention (IAS 2015), Vancouver; July 19-22, 2015; Vancouver, BC. Abstract no TUAC0204LB.

47. Liu AY, Kittredge PV, Vittinghoff E, et al. Limited knowledge and use of HIV post- and pre-exposure prophylaxis among gay and bisexual men. J Acquir Immune Defic Syndr. 2008;47(2):241-247.

48. Barash EA, Golden M. Awareness and use of HIV pre-exposure prophylaxis among attendees of a seattle gay pride event and sexually transmitted disease clinic. AIDS Patient Care STDS. 2010;24(11):689-691.

49. Golub SA, Kowalczyk W, Weinberger CL, Parsons JT. Preexposure prophylaxis and predicted condom use among high-risk men who have sex with men. J Acquir Immune Defic Syndr. 2010;54(5):548-555.

50. Mimiaga MJ, Case P, Johnson CV, Safren SA, Mayer KH. Preexposure antiretroviral prophylaxis attitudes in high-risk Boston area men who report having sex with men: limited knowledge and experience but potential for increased utilization after education. $J$ Acquir Immune Defic Synd. 2009;50(1):77-83.

51. Leonardi M, Lee E, Tan DHS. Awareness of, usage of and willingness to use HIV pre-exposure prophylaxis among men in downtown Toronto, Canada. Int J STD AIDS. 2011;22(12):738-741.

52. Nodin N, Carballo-Diéguez A, Ventuneac AM, Balan IC, Remien R. Knowledge and acceptability of alternative HIV prevention bio-medical products among MSM who bareback. AIDS Care. 2008;20(1):106-115.

53. Poynten IM, Jin F, Prestage GP, Kaldor JM, Imrie J, Grulich AE. Attitudes towards new HIV biomedical prevention technologies among a cohort of HIV-negative gay men in Sydney, Australia. HIV Med. 2010;11(4):282-288. 
54. Holt M. HIV pre-exposure prophylaxis and treatment as prevention: a review of awareness and acceptability among men who have sex with men in the Asia-Pacific region and the Americas. Sex Health. 2014; 11(2):166-170.

55. Smith DK, Toledo L, Smith DJ, Adams MA, Rothenberg R. Attitudes and program preferences of African-American urban young adults about pre-exposure prophylaxis (PrEP). AIDS Educ Prev. 2012;24(5): 408-421.

56. Galea JT, Kinsler JJ, Salazar X, et al. Acceptability of pre-exposure prophylaxis as an HIV prevention strategy: barriers and facilitators to pre-exposure prophylaxis uptake among at-risk Peruvian populations. Int J STD AIDS. 2011;22(5):256-262.

57. Mimiaga MJ, Closson EF, Kothary V, Mitty JA. Sexual partnerships and considerations for HIV antiretroviral pre-exposure prophylaxis utilization among high-risk substance using men who have sex with men. Arch Sex Behav. 2014;43(1):99-106.

58. Rawlings K, Mera R, Pechonkina A, et al. Status of Truvada (TVD) for HIV pre-exposure prophylaxis in the United States: an early drug utilization analysis. Presented at: 53rd Interscience Conference on Antimicrobial Agents and Chemotherapy (ICAAC 2013). September 10-13, 2013; Denver. Abstract H-663a.

59. Idoko J, Folayan MO, Dadem NY, Kolawole GO, Anenih J, Alhassan E. "Why should I take drugs for your infection?": outcomes of formative research on the use of HIV pre-exposure prophylaxis in Nigeria. BMC Public Health. 2015;15(1):349.

60. Jackson T, Huang A, Chen H, Gao X, Zhong X, Zhang Y. Cognitive, psychosocial, and sociodemographic predictors of willingness to use HIV pre-exposure prophylaxis among Chinese men who have sex with men. AIDS Behav. 2012;16(7):1853-1861.

61. Populations at Higher Risk for HIV: Racial and Ethnic Health Inequities [webpage on the Internet]. Atlanta: Centers for Disease Control and Prevention; 2014 [updated December 9, 2014]. Available from: http:// www.cdc.gov/nchhstp/newsroom/HIVFactSheets/Epidemic/inequities. htm. Accessed September 30, 2015.

62. Krakower D, Mayer KH. Engaging healthcare providers to implement HIV pre-exposure prophylaxis. Curr Opin HIV AIDS. 2012; 7(6):593-599.

63. White JM, Mimiaga MJ, Krakower DS, Mayer KH. Evolution of Massachusetts physician attitudes, knowledge, and experience regarding the use of antiretrovirals for HIV prevention. AIDS Patient Care STDS. 2012;26:395-405.

64. Maznavi KHD, Bredeek F. Pre-exposure prophylaxis (PrEP) for HIV: an online survey of HIV healthcare providers evaluating their knowledge, perception, and prescription of PrEP. In: 49th Annual Meeting of the Infectious Diseases Society of America; 2011; Boston, MA. Abstract 011 .
65. Karris MY, Beekmann SE, Mehta SR, Anderson CM, Polgreen PM. Are we prepped for preexposure prophylaxis (PrEP)? Provider opinions on the real-world use of PrEP in the United States and Canada. Clin Infect Dis. 2014;58(5):704-712.

66. Sachdev DD, Stojanovski K, Liu AY, Buchbinder SP, Macalino GE. Intentions to prescribe preexposure prophylaxis are associated with self-efficacy and normative beliefs. Clin Infect Dis. 2014;58(12): $1786-1787$.

67. Mimiaga MJ, White JM, Krakower DS, Biello KB, Mayer KH. Suboptimal awareness and comprehension of published pre-exposure prophylaxis efficacy results among physicians in Massachusetts. AIDS Care. 2014;26(6):684-693.

68. Calabrese SK, Earnshaw VA, Underhill K, Hansen NB, Dovidio JF. The impact of patient race on clinical decisions related to prescribing HIV pre-exposure prophylaxis (PrEP): assumptions about sexual risk compensation and implications for access. AIDS Behav. 2014; 18(2):226-240.

69. Vissers DC, Voeten HA, Nagelkerke NJ, Habbema JD, de Vlas SJ. The impact of pre-exposure prophylaxis (PrEP) on HIV epidemics in Africa and India: a simulation study. PLoS One. 2008;3(5):e2077.

70. Marcus JL, Glidden DV, Mayer KH, et al. No evidence of sexual risk compensation in the iPrEx trial of daily oral HIV pre-exposure prophylaxis. PLoS One. 2013;8(12):e81997.

71. Martin M, Vanichseni S, Suntharasamai P, et al. Risk behaviors and risk factors for HIV infection among participants in the Bangkok tenofovir study, an HIV pre-exposure prophylaxis trial among people who inject drugs. PLoS One. 2014;9(3):e92809.

72. Liu AY, Vittinghoff E, Chillag K, et al. Sexual risk behavior among HIV-uninfected men who have sex with men participating in a tenofovir preexposure prophylaxis randomized trial in the United States. J Acquir Immune Defic Synd. 2013;64(1):87-94.

73. Wilton J, Senn H, Sharma M, Tan DHS. Pre-exposure prophylaxis for sexually-acquired HIV risk management: a review. HIV AIDS (Auckl). 2015;7:125-136.

74. Grant RM, Anderson PL, McMahan V, et al. Uptake of pre-exposure prophylaxis, sexual practices, and HIV incidence in men and transgender women who have sex with men: a cohort study. Lancet Infect Dis. 2014;14(9):820-829.

75. Smith DK, Herbst JH, Zhang X, Rose CE. Condom effectiveness for HIV prevention by consistency of use among men who have sex with men in the United States. J Acquir Immune Defic Syndr. 2015;68(3): 337-344.

76. Cáceres CF, Koechlin F, Goicochea P, et al. The promises and challenges of pre-exposure prophylaxis as part of the emerging paradigm of combination HIV prevention. J Int AIDS Soc. 2015;18 (4 Suppl 3):19949.
HIV/AIDS - Research and Palliative Care

\section{Publish your work in this journal}

HIV/AIDS - Research and Palliative Care is an international, peerreviewed open-access journal focusing on advances in research in HIV, its clinical progression and management options including antivira treatment, palliative care and public healthcare policies to control viral spread. The journal welcomes original research, basic science,

\section{Dovepress}

clinical \& epidemiological studies, reviews \& evaluations, expert opinion \& commentary, case reports \& extended reports. The manuscript management system is completely online and includes a very quick and fair peer-review system. Visit http://www.dovepress.com/ testimonials.php to read real quotes from published authors. 